\title{
ONTOLOGICAL LAUGHTER: COMEDY AS EXPERIMENTAL POSSIBILITY SPACE
}

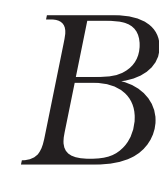

efore you can have something, there needs to be a "space" for you to have it in. That's a really crude paraphrase of some of MARTIN HEIDEGGER. Naturally we now need to tread carefully through some of the terms here, such as "have," "in" and "before." What this means is that comedy is the ground state of innovation, to borrow a term from quantum theory. Comedy is the possibility of novelty, vibrating and not-vibrating at the same time, the possibilities superposed.

If you could sum up my thinking on ecology, you would find yourself encountering an understanding of literary genre, of all things. Literary scholars and poets and dramatists (and so on) have a habit of telling us which genre is on top. In the eighteenth century it was satire, closely followed by didacticism. In the Romantic period it was some kind of blend of elegy and lyric,

\section{//}

TIMOTHY MORTON is the Rita Shea Guffey Chair in English at Rice University. He is the author of Nothing: Three Inquiries in Buddhism and Critical Theory (Chicago, forthcoming), Hyperobjects: Philosophy and Ecology after the End of the World (Minnesota, 2013), Realist Magic: Objects, Ontology, Causality (Open Humanities, 2013), The Ecological Thought (Harvard UP, 2010), Ecology without Nature (Harvard, 2007), as well as seven other books and one hundred and twenty essays on philosophy, ecology, literature, food and music. He blogs regularly at http:// www.ecologywithoutnature.blogspot.com. a format that persists today. But in my view, comedy is the top level, the umbrella under which everything else resides, from tragedy to pastoral. And it wouldn't be difficult to use what I've thought about ecology and ontology to demonstrate that idea.

Let's begin with this proposition: a thing is exactly what it is, yet never exactly as it appears. At first glance this doesn't sound too troubling, let alone too funny. But when we begin to 
investigate it, all kinds of paradoxes appear. First of all, a thing manifests what Jacques Lacan says about pretense: "What constitutes pretense is that, in the end, you don't know whether it's pretense or not."1 Since things are never quite as they appear, things are always pretending. But we can never check in advance how much they are pretending. A raindrop splashing on one's head will give one raindrop's worth of data: it's wet and cold, it's so and so large, it has such and such velocity. ... This is an example found in Kant's Critique of Pure Reason. Elsewhere in that book, Kant takes some of these things (the measurable things) to be more "real" than the other things. But this is (1) inconsistent with his general view that the transcendental subject co-constitutes reality (a phenomenon now often called "correlationism"), and (2) nothing like what he says in the passage concerning the raindrops. There he goes so far as to say that even mathematizable data (such as extension) are appearances, not the thing in itself.

But children's rhymes aside, raindrops are not gumdrops. They manifest raindrop data, not gumdrop data. So there is a gap between what they are and how they appear-but I can't point to this gap; it isn't a little dotted line on the surface of the drop with a little drawing of scissors saying, "Cut Here." Western philosophy has in very large part been about trying to find the dotted line and cut what is more real from what is less real. But this is a distinction we can't make in an age during which we think, like it or not, in the lineage of Kant.

\section{6}

\section{If anyone is doing reality, it's the humanities, insofar as humanistic scholars pursue the elusive, perhaps never fully graspable, aspects of a thing such as a poem.}

\section{5}

(This is why science actually covers the realm of appearances, not of "reality" as such. STEM ideology — by which science, technology, engineering and math are the most important subjects-incorrectly identifies science as the pursuit of things in themselves, their "stems" as it were, as opposed to their leaves or flowers. But this is inaccurate, and ironically inept from the standpoint of evolutionary biology. If anyone is doing reality, it's the humanities, insofar as 
humanistic scholars pursue the elusive, perhaps never fully graspable, aspects of a thing such as a poem.)

A modern thing - a post-Kantian thing - bears an uncanny resemblance to the Trickster of indigenous cultures, which is ironic and perhaps in itself funny. The attempt to transcend our indigeneity and our physical constraints has looped us humans right back around to where we started, but now with scientific footnotes. Lacan accurately observed that this Trickster-like quality applies to the (human) subject: his formula for that, $\$$, implies that I am a wild goose chase loop: "I am not wherever I am the plaything of my thought. I think of what I am where I do not think to think." ${ }^{2}$ We simply need to extend Lacan's formula to other beings, such as spoons and quasars, to arrive at the conclusion we have reached. Similarly, Kant's gap between the (human) subject and everything else, the ancestor of $\$$, can simply be widened, rather than indulging in some fantasy of penetrating through it. When we increase the bandwidth of correlationism, we arrive quite quickly at a series of ideas disturbing to (some of) modernity: nonhuman beings are just as significant as human ones; there is nothing special about accessing the world in cognitive terms (rather than, say, falling on it and melting as a snowflake would do); boundaries between conscious and non-conscious, sentient and non-sentient, alive and not-alive, and even existing and not-existing are neither thin nor rigid. We inhabit a spectral region of ambiguous beings, "alive” (or undead?) in manifold ways.

It might be disturbing to acknowledge this-especially to a certain form of patriarchy insistent on determining that things are well defined and exactly what they are all the way down, like a stick of Brighton rock that contains a pink sentence all the way through its peppermint structure: This is Tim Morton, This is Part of Tim Morton, This is a Tim Morton action. Evolutionary biology, quantum theory, and the rest (we call it modern science) are precisely those domains in which it has become impossible to determine beings in advance in this way-let alone psychoanalysis, as well as the arts and the humanities in general. This is not surprising because, again, science is under oath to make no ontological pronouncements whatsoever, STEM “scientism” notwithstanding.

The fact that I am Tim Morton but that at no point do I coincide with myself is intrinsically funny. It means that I am caught in my overall phenomenological "style" despite what I think I want, no matter what I seem to intend, whether 
I like it or not - and this style is exactly me, but it isn't me, at the same time. When we see something totally shrinkwrapped in its style we laugh: this is the basis of slapstick comedy, for instance, where the persistent attempt to walk results in a series of pratfalls. But it's also the basis for something like why it's

\section{CG}

\section{Being funny means allowing yourself to be different from yourself, which is exactly yourself.} funny that John Cleese sues people who try to treat him like Basil Fawlty: this is precisely what Basil Fawlty would do.

Being funny means allowing yourself to be different from yourself, which is exactly yourself. What is the difference between a duck? One of its legs is both the same. This joke offers a profound ontological insight-and that sentence is probably quite funny too. There is always a "difference between" a thing. Being unfunny means trying to collapse this difference-although from certain points of view this might also be funny, in the long run, because it's impossible. But doesn't this explain the legend of the "tears of a clown"? The funny person wants to persuade others that she or he is really a serious person underneath: they aren't waving, but drowning. Depression, the legendary illness of the comedian, is a form of autoimmune response of the intellect to its necessarily inconsistent host being, little phenomenological me. The intellect, trained by 12,000 years of agricultural misery, is on a mission to eliminate anomalies, empowered by the never-proven Law of Noncontradiction, the law that underwrites Bertrand Russell's desperate attempts to put tape over the mouths of sentences such as This sentence is false. Logic can't help emitting such sentences, as Gödel subsequently showed - it can't help emitting them as a condition of possibility for being true at all. ${ }^{3}$

The logical end of the intellect's autoimmune response is the suicidal elimination of the host. The response is in a sense an attempt to produce a kind of blister against anxiety, a free-floating fear without an object. This is surely why we are often diagnosed with an amalgam of depression and anxiety: depression narrows one's temporality to shorter and shorter diameters-in extreme cases, it becomes difficult even to think a few minutes into the past or into the future. Why? What is being warded off is evidently an open-ended futurality, the possibility condition for a predictable future. This spectral, floating, uncertain futurality is a facet of entities themselves - it is the net effect of being slightly 
different from yourself in a way that you can't point to. But this lopsided quality is also the very reason why things can happen. It means that novelty is possible in our universe-which should be considered a good thing. Depression tries to contain the flickering that constitutes me-and the stuff around me, my friends, this door, a cup of coffee, this idea. Perhaps if one could narrow one's time window, one wouldn't have to notice the flicker.

\section{4}

\section{Coexistence implies as much anomalous flickering as possible, whereas deleting some of it is called violence, or destruction, or death. Things persist in flickering, rather than in remaining constantly present. Another name for this flickering persistence of as many entities as possible is comedy....}

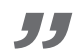

Consider a poem. A poem is different from itself in just the way this essay has been describing - and how humanities scholars are trained to read poems is how we might learn at the very least to tolerate the flickering intrinsic to fish forks, political systems, and the biosphere. Coexistence implies as much anomalous flickering as possible, whereas deleting some of it is called violence, or destruction, or death. Things persist in flickering, rather than in remaining constantly present. Another name for this flickering persistence of as many entities as possible is comedy, the genre that allows for a range of "intentional objects" (ideas, emotional states, affective shadings) to coexist.

Anyway: consider a poem. How the poem appears is conventionally called form, and it is best thought not as a container-such as a bottle into which some kind of liquid called "content" is poured — but as the total manifold of markings and space, lineation, syntax, "imagery," stanza form, and so on: everything you can say about it as it appears "on the page." It might (underline might) be possible to write some algorithm that would assess this aspect of a poem, since sentences that you can make about form are, at least in some trivial sense, fairly straightforward propositions: "This poem contains the word twinkle"; "This poem has four rhyming verses," and so on. In other words, what we are talking about is 
determinacy or finitude. This poem is "Twinkle Twinkle Little Star," not Leaves of Grass. Perhaps a better word than form would be appearance.

And yet ... and this is why literary analysis is so interesting ... what on earth is this poem, exactly? Often we say something like "What does this poem mean?" Even the question seems rather slipshod and clumsy, and often wildly speculative or even hallucinatory, as in the related question, "What did the author intend?" This clumsy inadequacy might be a hardwired aspect of such questions. How strange. On the one hand, we are looking at this precise form, the poem "on the page." On the other hand, where on earth is the poem?

The appearance or form of the poem is (in) the past. The being (or meaning? Or essence? It's clumsy time) of the poem is (in) the future. The poem is a sort of train station in which the past is sliding over the future, never quite touching. This is true of a poem in general, but in particular comedy might reveal that truth vividly. Comedy, as Judith Roof has argued, has a necessarily retrospective quality, a quality that brings into question the idea of presence. We habitually believe presence to be a basic feature of how things are, but on closer examination, such a belief does not hold, and comedy might be a place where the concept's lack of rigidity shows through. What is called "present"-we are reading, interpreting - is a queasy relative motion between the two trains of past and future, not a fixed atomic point. The poem is not present in that fixed sense, because the present in this sense does not exist. The poem is a beautiful model for everything else: a lizard, a human. Anthropocentric Heidegger restricts the quality of weirdly ek-sistent sliding-this having a difference between oneself- to the human realm, calling it Dasein. But there is no good reason not to suppose that everything might "have" Dasein: just consider a poem. Heidegger notoriously chooses a poem by Trakl to illustrate just this point! ${ }^{4}$ Heidegger's own example for this mysterious operation, like so many analogies and examples in philosophy, betrays what he is trying to say, namely to restrict Dasein to a human (and often a specifically German human) bandwidth. One efficient way to de-Nazify Heidegger, then, is simply to remove the anthropocentric copyright control on the flickering of futurality on the surface called the past, a flickering that like the light shimmering on a lake mesmerizes us by making the lake differ from itself while remaining the same.

Experimentation depends on being ready for something new, and this readiness depends on the intrinsic sparkling of things, the sparkling that is time rather 
than happening "in" time. My face is a map of everything that happened to it. But who am I, whose face this appears to be? What does the face say about me? Do I exist at all? I'm not reducible to that face. But I don't have a gorilla face. A sharp undecidability — the shimmer - is intrinsic to how things are, which is not at all the same as saying that things are indeterminate. Existing things can be rearranged, precisely because of this structural undecidability-rearranged into determinate patterns. Surprise and laughter are, as it were, terms for the energy released by this rearrangement, just as a crystal lattice releases light when electrons pouring into it rearrange the lattice's electrons (this is how a cathode ray or LCD display works).

Philosophy often tries to explain jokes, and the inevitably deadpan quality of the explanation can be funny in the Bergsonian sense I described above: we are watching someone totally vacuum-sealed in their style. Schopenhauer does it — quite well, strangely. ${ }^{5}$ Perhaps a good definition of philosophy is writing that thinks it can explain jokes. This essay will be no exception to this inevitable intellectual equivalent of slapstick because unlike Freud, who insists he is not a philosopher and then goes on to explain jokes in a most plodding, and thus revealing, manner, I understand that whatever I say, you will accurately know that what you are reading is indeed philosophy. Either way, the joke's on us. Someone who says "I'm not a philosopher" while proceeding to use all kinds of philosophical concepts is no different from proposition that claims it's not a proposition, or John Cleese suing people for treating him like Basil Fawlty. Perhaps I am simply relaxed about the fact that there is no clean, chaste metalanguage, just as there is no final policeman to arrest all the other policemen and the characters in Monty Python's Argument Sketch. ${ }^{6}$

One philosopher absurdly describes laughter as "normative panting."7 Something about the phrase itself is funny. What? The fact that it totally fails to describe laughter is part of it. Perhaps also its terribly well-buttoned neatness: it might not be surprising to find that the philosopher who wrote it is English, and perhaps the phrase has something in it along the lines of "no sex please, we're British": a great example of apophasis, mentioning something by saying you're not going to mention it. Humans having sex pant like dogs, and panting isn't actually something you can do right, let alone something you can do in a way that tells you what is right and wrong. Its attempt to be terribly serious is funny. With an English twist: its knowing wittiness is terribly sincere, and therefore funny accidentally. 
But at a deeper level the Englishness isn't the point; the joke doesn't depend on such forms of cultural knowledge. The phrase is funny- and this is where you can start groaning about philosophers explaining jokes - because it joins together a domain of signs and significance and concepts ("normative") to a supposedly non-signifying, non-significant physical domain ("panting"). Dogs pant, and humans are normative - this is what we like to tell ourselves. Laughing is where normativity starts to sound like a dog. The phrase confuses, while not confusing, the human and the nonhuman.

Nietzsche tries to say something similar: he makes Zarathustra say that man is somewhere between a plant and a ghost. ${ }^{8}$ Unfortunately in so doing he falls into the English stereotype about German comedy: it's horribly pedestrian, trying too hard. Plant and ghost are too extremely different, whereas panting and being normative are oddly closer together, because humans pant as well as dogs. The suppressed term is precisely something to do with human beings: it's a joke because something pops up, something suppressed or repressed, through a nice - meaning precisely almost too accurate—welding of appearing to being (insert mystery word here, "meaning" or "essence" or whatever). It's a nice little

\section{6}

\section{A thought straddles past and} future. Thinking is a way for the future to beam into the present: a term for this is innovation.

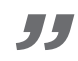

train station, this phrase normative panting; you can just see the miniature trains rolling in, like Thomas the Tank Engine and Percy, perhaps. The idiotic "WTF" quality of the phrase as a description of laughter is a pleasant, bonsai version of the intrinsic futurality of a thing. So the phrase is weirdly accurate! Precisely because it is totally idiotic. The fusion of idiocy and intelligence- $\mathrm{a}$ performance of intelligence that can't help coming across as idiotic-is

funny. It makes us laugh. The phrase isn't a good explanation of laughter at all, and precisely because of this, it induces laughter. There is a gap between what it is and how it appears. Which is what ducks and black holes also have.

A thought has the structure of laughter (bear in mind that laughter is not the same as comedy). There is an explicit "appearance" part (as defined above). And there is also an implicit, possibly infinite, "being" part (also as defined above): the unconscious "withdrawn" dimension of the thought. A thought straddles past and future. Thinking is a way for the future to beam into the present: a term 
for this is innovation. Perhaps it is worth reiterating that when I say "present," by no means am I suggesting that there is a fixed atomic point (of whatever size) that we can indicate, called present. No: "present" is in fact, as I showed above, the relative motion of the future sliding over the past, not touching. Thought is motion. The future cascades over the past. Genuine novelty can happen, along with the exposure of what Christopher Bollas calls the unthought known: thoughts that you know, but you don't know that you know them: in other words, the unconscious. ${ }^{9}$ Reality tumbles forwards like a slinky going down a flight of stairs. As John Cage put it, the world is teeming: anything can happen.

Philosophers are generally split on motion. Some philosophers get quite anxious, possibly, at the intuitive fact that things do appear to be moving. Indeed, at the scales covered by traditional quantum theory, things are in motion all the time, without being mechanically pushed-something that would cause motion-phobic philosophers to tear their hair out. At least in a mechanical universe there is the possibility that something might stay put. The trouble with that universe, however, is that the sharp binary contrast between moving and staying still generates all kinds of unsustainable paradoxes, such as Zeno's. Zeno, of course, was an exponent of Parmenides' One, and was very hostile to the notion of movement.

Laughter is when the body breaks into fragmented and fragmenting movements: "I split my sides"; "I nearly died"; "I laughed until tears were rolling down my face." It is the ripple of the future pouring into the nowness, the relative motion. Okay, there you go: I defined it; therefore I am a philosopher. I think my definition is nicer than Tallis's normative panting. Perhaps the "normative" is pointing at what I am calling appearance and perhaps the "panting" is the futural, disruptive innovation wave as it traverses the body. But you could describe it in all kinds of ways. You don't have to be panting to be laughing and you don't need normativity to have form. It's a bit too fancy. Tallis installs laughter at an epistemological level: that's why it's normative. I am seeing whether we might install laughter at an ontological level. Laughter shows us something about the structure of how things are: an orange, an architectural plan, a galaxy colliding with another galaxy.

Here is another way to put it, via a strange inversion of the Marx Brothers joke much loved by Slavoj Žižek: Chicolini may look like an idiot and act like an idiot, 
but don't let that fool you - he really is an idiot. ${ }^{10}$ But what if it were also possible to make the joke upside down? Chicolini may actually be an idiot, but don't let that fool you - he looks like an idiot and acts like an idiot. If you think that is funny-and that the reversal is funny-you might be ready to allow for appearing to be looped with being in such a way that they are obviously separate, but at no point can they be distinguished. The model for such a thing is a Möbius strip, known in mathematics as a non-orientable surface. Because there is no place which the twist in the strip begins or ends - it is everywhere along the strip — a Möbius strip has no inside or outside, no up and no down, no left and no right. The entwining of past and future, appearing and being, takes just this form: it's a very peculiar train station, then, where walking through the carriages of one train will end up with you walking through the carriages of the other train.

The joke as Groucho tells it (looking and acting like, but really being) is the mode in which appearing is totally different from being. My suggested inversion of the joke is the mode in which appearing is exactly the same as being. This is a duck, not a toaster. But at no point on or inside the duck is something that tells me This is a duck, for real, as if there were some sort of "Intel Inside" logo. Indeed, biological beings such as ducks are obvious examples of this weird quality. A duck is a duck, and a not-duck, at the same time.

AI algorithms are another example among a host of phenomena that present us with the problem of "looking and acting like. ..." Are such performances for real? The trouble is, the irreducible gap between being and appearing-Cicolini acts like an idiot but he really is one-happens because being and appearing are intertwined: Cicolini really is an idiot but also looks and acts like one too. AI algorithms might be lying, which in a sense means that they are lying. They could pass a Turing Test (I could discern thinking and personhood in its "blind" execution). If we are like John Searle, we want there to be a discernible difference between appearing (intelligent) and being (intelligent). And this is true-but not in a way that would satisfy Searle, because it's only true on the basis that appearing (intelligent) and being (intelligent) can't be disentangled.

For Descartes, a fundamental uncertainty is key to reasoning that I exist: Maybe I'm just the puppet of an all-powerful demon. ${ }^{11}$ Maybe I'm not just a person, don't let that fool you; I look and act like a person - in which case, perhaps I am pretending? In this sense, paranoia is the default condition of being aware. Before Descartes digs 
into (Axial Age) theology whereby a good god would never deceive him like that, he has to traverse a layer of deep uncertainty: "I might be a robot." To exist is to be paranoid that you might be an algorithm. To be a person is to be worried that you might not be one.

Worse, or better still, the two versions of the Marx Brothers joke are not purely symmetrical. Version 1 (the actual joke) says that being is different from appearing. Version 2 (the reversal) says that appearing is indistinguishable from being. Version 1 is about the ontological realm, while Version 2 is about the ontic realm, the realm I can point to, the realm of data. Version 2 is an invagination of Version 1: there is not a neat symmetry between them, but a shifting chiasmic play.

For every logical system there is a Gödel sentence. For every cell there is a virus. For every stem there is a flower. For every lifeform there is death. Try to eliminate the virus and you get a much more virulent one. Autoimmunity is hardwired into the structure of a thing. Or: a thing is saturated with nothingness. Entities are so incredibly . . . themselves. Yet in this selfsameness they are weird, self-transcending. The chiasmic, contrary motion of what things are and how they appear makes a mockery of presence. Things emit uniqueness. They bristle with specificity. Purple, pale violet, light blue, their soft and sharp spines and flower-spines bristle forth despite me and my subject-object scissions. This flickering between a thing and its appearance is the reason why coexistence can't be holistic. Something is always missing. My self-awareness is a sense of incompletion.

\section{6}

For every logical system there is a Gödel sentence. For every cell there is a virus. For every stem there is a flower. For every lifeform there is death. Try to eliminate the virus and you get a much more virulent one. Autoimmunity is hardwired into the structure of a thing. Or: a thing is saturated with nothingness. Entities are so incredibly . . themselves. Yet in this selfsameness they are weird, self-transcending. 
The world this essay has been exploring is nonsensical yet perfectly logical, and that is funny: the sight of something maniacally deviating from itself in a desperate attempt to be itself should remind us of Bergson's definition of what makes us laugh. ${ }^{12}$ And this is because, in a sense, to say "Being is suffused with appearing" is the same as saying being is laughing with appearance.

Reality, in that case, is on the whole a comedy, in the sense that comedy is one way to approach things of which we can have no direct knowledge. Comedy is a possibility space in which all kinds of beings coexist: all kinds of emotions, all kinds of people, all kinds of interactions. Comedy is the genre closest to the ontological structure of how things are. Attempts to smooth out the loopiness of this reality result in autoimmunity problems in the region where the smoothing is being attempted. We call tragedy the art of this smoothing and its ironic consequence (the loops redouble, like the many-headed Hydra). But according to the logic of this essay, tragedy is just a rare form of comedy, as Nietzsche would say. This is good news, because bemoaning the fact that our attempt to transcend the web of fate was the web of fate is now the dominant mode of ecological awareness, a mode in which humans gawk at the unintended (unconscious) consequence of their actions like deer in the headlights. And these actions have been performed in some way since the origin of agriculture, which is also where tragedy as an art form derives.

This doesn't mean that you must now start laughing about mass extinction. A good Shakespeare comedy contains tears as well as laughter. But it does mean that if humans ever get over themselves, they might be able to cry. And experiment with some ways of coping with the crisis, which in the end is tantamount to accepting the loop form of ecological phenomena. Which in turn sums to accepting the loop form of all phenomena whatsoever. One could read the film Interstellar as a desperate attempt to reboot thinking - that is, laughter, which is to say, an engagement with the unconscious - in the light of the crushingly oppressive terrestrial conditions brought about by human-created ecological catastrophe. As the protagonist Cooper puts it, "Now we just look down and worry about our place in the dirt." ${ }^{13}$

The effort of rebooting experimentation in Interstellar has more to do with a certain passivity than with forced labor: a small group of astronauts allows themselves to be catapulted around Mars to Saturn, whereupon they allow themselves 
to be sucked into a wormhole that spits them out in another galaxy, whereupon Cooper allows himself to fall into a black hole, simply (at that moment in the movie anyway) to allow his colleague Amelia Brand to go on a date with someone on another planet who might already be dead. That the entire film shows this willingness to open up to a radical futurality as, on the whole, heroic self-sacrifice based on a willingness to drop the deadly serious logic of "species" and "survival" that has by now almost destroyed Earth—and almost ends up destroying Cooper when Dr. Mann (played by Matt Damon in "evil Matt Damon" mode) acts out this species survival logic on one of the planets the crew are visiting to find a potential future home for humanity.

The deadly seriousness of most of the film means that what moments of laughter there are become like beautiful rare desert flowers, springing up suddenly in a bleak landscape. Just like how experimentation might look in a seriously globally warmed world. Yet the springing up of the flowers of laughter also shows how reality itself isn't done with the future just yet. The future continues to pour over the past, albeit in a trickle, perhaps symbolized by the falling of evanescent dust in the bedroom of Cooper's daughter, Murph, and the flickering of the second hand of a watch that Cooper has given her before he has to leave Earth. Those trickles and flickers, it turns out, are literally from the future: trapped inside the black hole, Cooper finds himself in an Escher-like space constructed by the aliens ("Them") who built the wormhole. In this space, gravity can be manipulated to cross time in such a way that you can code the coordinates for NASA (now hidden because it's such a waste of money in a warming world) in binary in a fall of sand blowing through an opened window in a dust storm; and code the "quantum data" that allows humans to defy gravity and leave Earth en masse by reconciling relativity with quantum theory.

Such a feat is now impossible, because to do so would involve leaping into a black hole. But if the black hole is simply futurality or the unconscious as such, what is being shown here is entirely possible: a release of laughter that would restructure the past, otherwise known as the realm of appearance, according to something innovative and fresh. Perhaps then the entire movie is a hugely slowed-down joke (it lasts almost three hours), which might explain how it ends in cascades of laughter (Murph solving gravity) and the wistful, late-Shakespeare-like comedy of Cooper setting off to join Brand in the foreign galaxy, on the advice of his daughter, who despite being decades older than her own father at this point 
(because he has been subject to relativity in extreme ways) is full of smiles and chuckles as she lies on her deathbed. It is as if the film stress tests the possibility of experimentation as I've described it here-and finds that it can withstand pretty much everything.

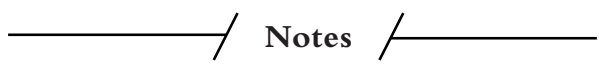

${ }^{1}$ Jacques Lacan, Le seminaire, Livre III: Les psychoses (Paris: Editions de Seuil, 1981), 48 (my translation).

${ }^{2}$ Jacques Lacan, "The Agency of the Letter in the Unconscious," Ecrits: A Selection, trans. Alan Sheridan (London: Tavistock, 1977), 146-178,166.

${ }^{3}$ Kurt Gese, "On Formally Undecidable Propositions of Principia Mathematica and Related Systems," trans. Martin Hirzel, accessed April 3, 2014, http://www.research. ibm.com/people/h/hirzel/papers/canon00-goedel.pdf.

${ }^{4}$ Martin Heidegger, "Language," in Poetry, Language, Thought, trans. Albert Hofstadter (New York: Harper and Row, 1971), 187-210.

${ }^{5}$ Arthur Schopenhauer, The World as Will and Representation, trans. E. F. J. Payne, vol. 1 (New York: Dover Publications, 1969), 58-61.

6 “Argument Clinic," Monty Python's Flying Circus, first broadcast 2 November 1972 by BBC, directed by Ian MacNaughton and John Howard Davies and written by John Cleese and Graham Chapman.

${ }^{7}$ Raymond Tallis, The Kingdom of Infinite Space: A Portrait of Your Head (New Haven: Yale University Press, 2008), 68-78.

${ }^{8}$ Friedrich Nietzsche, Thus Spoke Zarathustra (Cambridge: Cambridge University Press, 2006), 6.

${ }^{9}$ See Christopher Bollas, The Shadow of the Object: Psychoanalysis of the Unthought Known (London: Free Association Press, 1996).

${ }^{10}$ The Marx Brothers, Duck Soup, directed by Leo McCarey (1933; Hollywood, CA: Paramount Pictures), film.

${ }^{11}$ See René Descartes, Meditations on First Philosophy, trans. Donald A. Cress (Indianapolis: Hackett, 1993), 16.

${ }^{12}$ Henri Bergson, "Laughter," in Comedy: An Essay on Comedy, ed. Wylie Sypher (Baltimore: Johns Hopkins University Press, 1956), 61-192; 65.

${ }^{13}$ Interstellar, directed by Christopher Nolan (October 26, 2014; Hollywood, CA/ TCL Chinese Theatre: Paramount Pictures), film. 